\section{Sleep Bruxism, Awake Bruxism and Sleep Quality among Brazilian Dental Students: A Cross-Sectional Study}

Júnia Maria Serra-Negra, Ana Carolina Scarpelli, Débora Tirsa-Costa, Flávia

Helena Guimarães, Isabela Almeida Pordeus, Saul Martins Paiva
Department of Pediatric Dentistry and Orthodontics, UFMG - Federal University of Minas Gerais, Belo Horizonte, MG, Brazil

Correspondence: Dra. Júnia Maria Serra-Negra, Avenida Antonio Carlos 6627, 31270-901 Belo Horizonte, MG, Brasil. Tel: +55-31-3409-2433. e-mail: juniaserranegra@hotmail.com
The aim of the study was to evaluate the association of sleep bruxism, awake bruxism and sleep quality among dental students of the Federal University of Minas Gerais, Belo Horizonte, Brazil. A cross-sectional study was performed including 183 Brazilian dental students aged from 17 to 46 years old. The complete course curriculum consists of 9 semesters. Students enrolled in the first semester, the middle semester and the final semester of the course participated in the survey. The PSOI-BR (the Brazilian version of the Pittsburgh Sleep Questionnaire Index) was used for data collection. The PSQI-BR was distributed during lecture classes. Sleep bruxism and awake bruxism diagnosis was based on self-reported data. Descriptive analysis, Kruskal-Wallis, Mann-Whitney and Poisson regression with robust estimator were the statistical tests used. Sleep bruxism prevalence was $21.5 \%$ and awake bruxism prevalence was 36.5\%. Sleep duration components were associated with sleep bruxism ( $\mathrm{PR}=1.540 ; 95 \% \mathrm{Cl}$ : 1.00-2.37) and awake bruxism $(\mathrm{PR}=1.344 ; 95 \% \mathrm{Cl}: 1,008-1,790)$. There was an association between awake bruxism and habitual sleep efficiency component ( $\mathrm{PR}=1.323 ; 95 \% \mathrm{Cl}$ : 1.03-1.70). Sleep disturbance component and awake bruxism were associated ( $\mathrm{PR}=1.533 ; 95 \% \mathrm{Cl}: 1.03-2.27)$. Poor sleep quality was an important factor among dental students, who reported sleep bruxism as well as among those who presented awake bruxism.
Key Words: awake bruxism, parafunction, sleep bruxism, sleep disorder, sleep quality.

\section{Introduction}

Sleep is a physiological phenomenon with the fundamental function of physical and mental restoration (1-6). Consolidation of memory is strongly associated with the sleep quality, suggesting that sleep facilitates processing new information $(1,2)$. Poor quality of sleep can affect mood, attention, sensory registering, reasoning and other cognitive aspects that relate a person to his or her environment $(1,3)$. Poor quality of sleep may also be associated with environmental factors (4). Sleep deprivation may have a negative effect on the learning process, resulting in poor academic performance, and interfering with health (1-3,7-13).

Students have normally irregular sleep patterns, characterized by lateness at the beginning and end of sleep (7-14). The need for sleep, accumulation of extracurricular activities, preferences relating to the time for sleeping and the time to wake up may conflict with the academic demands (7-9,12-14).

Undergraduate students were more prone to situations of stress that affected quality of sleep (8). Such profiles of stress may result in sleep bruxism and/or awake bruxism (14), parafunctions that can affect oral and general health (15-17). Muscle pain, headaches, tooth wear, TMD and even loss of teeth are just some of the consequences of sleep bruxism and awake bruxism (14-17). The prevalence of sleep bruxism and awake bruxism among 18 years-old adolescents was $14.8 \%$ and $8.7 \%$ respectively (17). Family members live in close proximity to the individual who suffers from these parafunctions, and sometimes are unaware of the correct etiology of the process (18). This lack of knowledge, with distortions of concepts, compromises the professional's search for suitable treatment (18).

Sleep bruxism is a sleep-related movement disorder parafunction and may be associated with other sleep disorders (4-6). A search the PUBMED and SCOPUS scientific electronic databases in May 2014 using the keywords sleep bruxism, awake bruxism, sleep quality and undergraduate students did not, however, retrieve studies that evaluated this association.

The aim of this study was to evaluate quality of sleep, sleep bruxism and awake bruxism among dentistry students at the Federal University of Minas Gerais comparing the behavior of students at the beginning, in the middle and at the end of their courses.

\section{Material and Methods}

Study Design and Sample

This study was approved by the Human Research Ethics Board of the Federal University of Minas Gerais, Brazil. 
A cross-sectional study was performed of a group of dental students from UFMG, in the campus of Belo Horizonte, Minas Gerais State in southeastern Brazil. The current course curriculum has a nine-semester duration. Three groups of students were evaluated: students in the first semester of the course, from the middle of the course $\left(4^{\text {th }}\right.$ semester) and from the last semester of the course. The choice of these groups is based on the aim of observing the behavior of students beginning a dentistry course $\left(1^{\text {st }}\right)$, those in the middle of the course $\left(4^{\text {th }}\right)$ and therefore beginning to treat patients at university dental clinics, and those close to finish their dentistry course. Data were collected from February to July 2013.

The target sample population of the study comprised 183 undergraduate dental students aged from 17 to 46 years. Student participation in the study was voluntary.

\section{Data Collection}

The participants were approached during lecture classes. Once a consent form had been signed, the participants completed the Brazilian version of the PSOI (19). The questionnaire was applied three times in each class group, on three different occasions, in order to allow absent students to participate in the study. Students were additionally asked to answer two questions regarding sleep bruxism: "In the last 30 days, has anyone told you that you grind your teeth while sleeping?" and awake bruxism: "In the last 30 days have you noticed clenching your teeth while awake and not chewing food?"

\section{PSOI-BR Instrument}

The original PSOI was developed in the USA (20). This instrument assesses the previous 30 days sleep quality. The PSOI consists of 19 self-rated questions and five questions rated by another person, perhaps a roommate. These last five questions are used for clinical information only and are not tabulated in PSOI scoring, according to the regulations set by the authors (20). The 19 self-rated questions assess factors related to sleep quality, including estimates of sleep duration and latency, and the frequency and severity of specific sleep-related problems. These 19 items are grouped into seven components, each of them scored equally on a 0-3 scale. The seven components of the $\mathrm{PSOI}$ are standardized versions of areas routinely assessed in clinical interviews of patients with sleep/wake complaints. These components are: sleep quality, sleep latency, sleep duration, habitual sleep efficiency, sleep disturbances, use of sleeping medications and daytime dysfunction. The components are totaled to yield a global PSOI score. Scores greater than five indicate inferior sleep quality (20).

The PSOI-BR was validated among 114 patients of the Hospital das Clinicas in the city of Porto Alegre in southern Brazil. The patients were between 18 and 65 years old (19). It is an easy instrument to use and recommended for epidemiological surveys (21).

\section{Statistical Analysis}

For the initial exploratory analysis, descriptive analyses of the sample and of the PSOI-BR components were performed. The Kolmogorov-Smirnov test was used to assess the normality of the distribution of the PSOI-BR components and global scores, which demonstrated a non-normal distribution. The association between PSQI-BR components and global scores and different semesters of the dentistry course were evaluated using the Kruskal-Wallis and Mann-Whitney tests. Correlations between component-global PSOI-BR score and age were carried out using the Spearman Correlation Coefficient. Poisson regression with robust variance was employed for the evaluation of associations between sleep bruxism and awake bruxism and component-global PSOI-BR, as well as for the estimation of prevalence ratios (PR) and respective 95\% confidence intervals. For this analysis the outcome variables sleep bruxism and awake bruxism were dichotomized as "no" (individuals who reported that they had not ground their teeth while asleep or clenched their teeth while awake in the last 30 days) and "yes" (individuals who reported that they had ground their teeth while asleep or clenched their teeth while awake in the last 30 days). The level of significance was set to $5 \%(p<0.05)$. Data analysis was performed using the Statistical Package for Social Sciences program (SPSS for Windows, version 21.0, SPSS Inc, Chicago, IL, USA).

\section{Results}

From a total of 222 students enrolled in the $1^{\text {st }}, 4^{\text {th }}$ and last semester of the dental course, 183 participated in the study (82.4\%). The $39(17.6 \%)$ students who did not participate in the study did so because they were absent from class in the days when the PSOI-BR was applied or they did not deliver the questionnaire with all questions filled out. A total of 144 women (78.7\%) and 39 men $(21.3 \%)$ participated in the study (Table 1). The mean age of the students was 21.2 years $(S D=3.7)$. There were three groups of students: of the 72 students in the first semester of the course 63 (87.5\%) agreed to participate; of the 88 enrolled in the middle semester of the course, 64 participated $(72.7 \%)$ and of the 62 students in the last semester of the course, 56 participated (90.3\%). These response rates were considered to be good.

A total of 28 students subjectively classified their sleep quality as very good (15.4\%), 105 as good (57.7\%), 47 as bad (25.8\%) and only two as very bad (1.1\%). Participants reported that they had on average 6.8 hours of sleep per 
night during the previous month, with a minimum of four hours and maximum of 11 hours per night $(S D=1.1)$. Only 38 students $(20.8 \%)$ reported having equal to or more than eight hours of sleep per night. The prevalence of sleep bruxism was $21.5 \%$ and $36.5 \%$ of students reported awake bruxism (Table 1).

Table 1. Descriptive analysis: demographic and clinical characteristics of the sample

\begin{tabular}{|c|c|c|}
\hline Sample categorization & $\mathrm{N}$ & $\%$ \\
\hline \multicolumn{3}{|l|}{ Gender } \\
\hline Female & 144 & 78.7 \\
\hline Male & 39 & 21.3 \\
\hline \multicolumn{3}{|l|}{ Age (median) } \\
\hline 17 - 21 years & 106 & 58.6 \\
\hline $22-46$ years & 75 & 41.4 \\
\hline \multicolumn{3}{|l|}{ Course period } \\
\hline First semester & 63 & 34.4 \\
\hline Middle semester & 64 & 35.0 \\
\hline Last semester & 56 & 30.6 \\
\hline \multicolumn{3}{|c|}{ Time required to fall asleep in previous month } \\
\hline$\leq 15 \min$ & 98 & 53.8 \\
\hline $16-30 \mathrm{~min}$ & 69 & 38.0 \\
\hline $31-60 \min$ & 14 & 7.7 \\
\hline$>60 \min$ & 01 & 0.5 \\
\hline \multicolumn{3}{|c|}{ Hours of sleep per night in previous month } \\
\hline$>7 \mathrm{~h}$ & 50 & 27.3 \\
\hline$\geq 6 \mathrm{~h}$ and $\geq 7 \mathrm{~h}$ & 110 & 60.1 \\
\hline$\geq 5 \mathrm{~h}$ and $>6 \mathrm{~h}$ & 22 & 12.0 \\
\hline$<5 \mathrm{~h}$ & 01 & 0.5 \\
\hline \multicolumn{3}{|l|}{ PSQI-BR global score } \\
\hline 1 to 4 & 42 & 23.0 \\
\hline 5 to 6 & 64 & 35.0 \\
\hline 7 to 11 & 77 & 42.0 \\
\hline \multicolumn{3}{|c|}{ Awake bruxism (previous month) } \\
\hline First semester & 12 & 19.0 \\
\hline Middle semester & 27 & 42.9 \\
\hline Last semester & 27 & 49.1 \\
\hline \multicolumn{3}{|c|}{ Sleep Bruxism (previous month) } \\
\hline First semester & 06 & 9.5 \\
\hline Middle semester & 16 & 25.4 \\
\hline Last semester & 17 & 30.9 \\
\hline
\end{tabular}

The study showed that 155 undergraduate students had habitual sleep efficiency $>85 \%$, and $8.2 \%$ of students took more than $30 \mathrm{~min}$ to fall asleep at night. Ten participants $(5.5 \%)$ had taken medicine to help them sleep during the previous month. When asked about the difficulty of staying awake while driving, eating meals or engaging in social activity, 79.2\% reported daytime dysfunction (Table 2).

The results demonstrated that $60.1 \%$ of students had an overall PSOI-BR score greater than five. The scores ranged from 1 to 12 points, with a total sample mean of 6.08 $(S D=2.18)$ and a median of 6.00 . Statistically significant differences were observed between the different groups of the dentistry undergraduate course in sleep categories of duration (first vs middle; $p=0.003$; middle vs last semester; $\mathrm{p}<0.001$ ), daytime dysfunction components (first vs middle semester; $p<0.001$ ) and PSOI-BR global score (first vs middle semester; $p=0.007)$. Kruskal-Wallis and Mann-Whitney tests were used for statistical analysis (Table 3).

Spearman's Correlation Coefficient between PSOI-BR global and component scores and age were obtained (Table 4). Sleep latency $(r=0.146 ; p=0.050)$; sleep duration $(r=0.180 ; p=0.015)$ and habitual sleep efficiency $(r=0.146$; $p=0.049$ ) components correlated positively with age in the total sample (Table 4).

Sleep duration component was associated with sleep bruxism ( $\mathrm{PR}=1.540 ; 95 \% \mathrm{Cl}=1.002-2.367)$ and with awake bruxism ( $\mathrm{PR}=1.344 ; 95 \% \mathrm{Cl}=1.008-1.790)$. Sleep bruxism was associated with subjective sleep quality $(P R=6.134$; $95 \% \mathrm{Cl}=2.603-14.454)$ and sleep duration ( $\mathrm{PR}=3.536$; $95 \% \mathrm{Cl}=1.192-10.486$ ) components in students from the first semester (Table 5). Awake bruxism was statistically associated with habitual sleep efficiency $(P R=1.977$; $95 \% \mathrm{Cl}=1.041-3.752)$ and sleep disturbance ( $\mathrm{PR}=3.490$; $95 \% \mathrm{Cl}=1.362-8.941)$ components. Awake bruxism was associated with habitual sleep efficiency ( $\mathrm{PR}=1.323 ; 95 \%$ $\mathrm{Cl}=1.027-1.705)$ and sleep disturbance $(\mathrm{PR}=1.533 ; 95 \%$ $\mathrm{Cl}=1.033-2.275$ ) components (Table 5).

\section{Discussion}

The proportion of students with poor sleep quality in the study population was generally consistent with the results of previous studies that used the PSOI $(10,11)$. However, the findings of the present study differed from those of previous studies which evaluated the sleep quality of university students in that more than half of them reported poor quality of sleep $(3,8,13)$. This discrepancy may be explained by cultural differences, as one cited study involving 540 undergraduate students in Lebanon (3) and another 241 undergraduate students in Nigeria (8). Both studies in Lebanon and in Nigeria used a similar age range as in the present study (average of 21 years), but the samples were much larger and collected information from various 
university departments, not just dentistry students $(3,8)$.

Some participants in the present study had taken medicine to help them sleep. Among the university students who participated in the study in Ethiopia, 8.7\% reported using sleep medication (11) while among Palestinians only $1 \%$ used such medication (9). The cultural differences of the population may explain this discrepancy in sleep characteristics (3).

Table 2: Brazilian Portuguese version of Pittsburgh Sleep Quality Index (PSQI-BR): scores and components' descriptive analyses

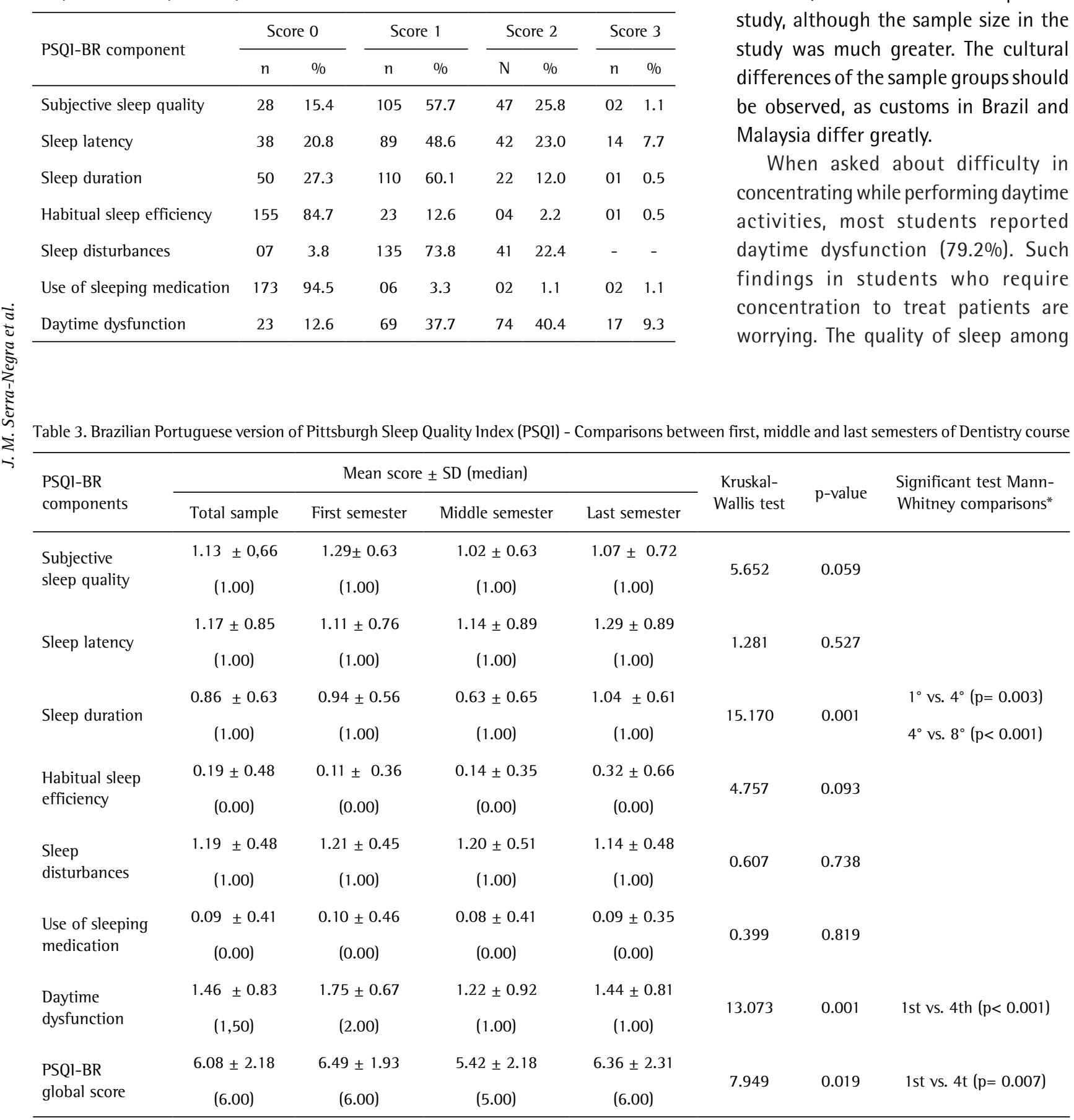

$\mathrm{SD}=$ standard deviation; $\mathrm{p}$-value=probability value. *Statistical significance at $\mathrm{p}<0.017$ based on the Mann-Whitney test.
The World Health Organization recommends a minimum of eight hours sleep per night as the ideal amount for a good quality night's sleep (4). The present study found that the mean amount of sleep of participants was $6.8 \mathrm{~h}$ per night. The results of the present study were similar to other studies that evaluated undergraduate students, and found that student tasks and high anxiety could influence the amount of sleeping hours per night (3,7-11). A study of 1118 university students in Malaysia reported that participants slept for more than $7 \mathrm{~h}$ per night (22). This study used the PSOI, the same used in the present study, although the sample size in the study was much greater. The cultural differences of the sample groups should be observed, as customs in Brazil and alaysia differ greatly. concentrating while performing daytime activities, most students reported aytime dysfunction (79.2\%). Such findings in students who require concentration to treat patients are worrying. The quality of sleep among 
medical and nursing students indicates difficulties in sleeping and poor quality of sleep of such students $(2,8,13)$.

There was a greater prevalence of awake bruxism (36.5\%) than sleep bruxism (21.5\%) among the students who participated in the present study. In a nine year longitudinal study of young Finns, percentage of sleep bruxism similar to the present study was found (21.7\%) (16). A study of 4235 Dutch adolescents reported prevalences of $14.8 \%$ for sleep bruxism and $8.7 \%$ for awake bruxism (19). It may be that this difference is the result of the age range studied by the authors, who evaluated adolescents aged between 12 and 18 years, while the present study evaluated undergraduate students aged from 17 to 46 years. Self-reported sleep bruxism and awake bruxism increases from adolescence to young adulthood (16).
When the PSOI-BR components were analyzed for the three groups of university students, it was found that students in the first semester scored higher than students in other semesters. University students in Ethiopia also displayed this behavior (11). The authors found higher scores among students in the second year of their course than those in the third and fourth years (11). A student who has recently entered the university is subjected to the pressures of choosing a profession and entering a new environment, which can increase his or her levels of anxiety and subsequently affect the quality of sleep (11).

The association between PSOI-BR components and the presence of sleep and awake bruxism was evaluated. There was an association between sleep bruxism and awake bruxism and sleep duration. Short duration of sleep can

Table 4. Component-global Brazilian Portuguese version of Pittsburgh Sleep Quality Index (PSQI-BR) score correlations with age

\begin{tabular}{|c|c|c|c|c|c|c|c|c|}
\hline \multirow{2}{*}{ PSQI-BR components } & \multicolumn{2}{|c|}{ Total sample } & \multicolumn{2}{|c|}{ First semester } & \multicolumn{2}{|c|}{ Middle semester } & \multicolumn{2}{|c|}{ Last semester } \\
\hline & $r$ & p-value & $r$ & p-value & $r$ & $p$-value & $\mathrm{r}$ & $\mathrm{p}$-value \\
\hline Subjective sleep quality & 0.045 & 0.545 & 0.109 & 0.396 & $0.274^{*}$ & 0.031 & 0.161 & 0.241 \\
\hline Sleep latency & $0.146^{*}$ & 0.050 & 0.082 & 0.501 & 0.202 & 0.115 & -0.044 & 0.745 \\
\hline Sleep duration & $0.180^{*}$ & 0.015 & $0.290^{*}$ & 0.021 & 0.066 & 0.612 & 0.243 & 0.071 \\
\hline Habitual sleep efficiency & $0.146^{*}$ & 0.049 & -0.041 & 0.752 & 0.141 & 0.274 & 0.177 & 0.192 \\
\hline Sleep disturbances & 0.116 & 0.120 & $0.314^{*}$ & 0.012 & 0.234 & 0.068 & -0.138 & 0.311 \\
\hline Use of sleeping medication & 0.001 & 0.986 & 0.114 & 0.372 & -0.171 & 0.184 & -0.064 & 0.640 \\
\hline Daytime dysfunction & -0.117 & 0.118 & -0.176 & 0.169 & 0.016 & 0.904 & -0.112 & 0.410 \\
\hline PSQI-BR global score & 0.142 & 0.056 & 0.202 & 0.112 & $0.281^{*}$ & 0.027 & 0.069 & 0.615 \\
\hline
\end{tabular}

$\mathrm{r}=$ Spearman's Rank Correlation Coefficient; $\mathrm{p}$-value=probability value. ${ }^{*}$ statistical significance at 0.05 . Age range

(Total sample: $17-46$ years; $1^{\text {st }}$. period: $17-46$ years; $4^{\text {th }}$. period: $18-32$ years; $8^{\text {th }}$. period: $21-38$ years).

Table 5. Association between sleep bruxism and awake bruxism and component-global Brazilian Portuguese version of Pittsburgh Sleep Quality lndex (PSQI-BR)

\begin{tabular}{|c|c|c|c|c|c|c|c|c|}
\hline \multirow{3}{*}{ PSQ1-BR components } & \multicolumn{3}{|c|}{ Sleep bruxism (no/yes) } & \multirow{3}{*}{$p$-value* } & \multicolumn{3}{|c|}{ Awake bruxism (no/yes) } & \multirow{3}{*}{ p-value* } \\
\hline & \multirow{2}{*}{ Unadjusted PR } & \multicolumn{2}{|c|}{ [Cl 95\%] } & & \multirow{2}{*}{ Unadjusted PR } & \multicolumn{2}{|c|}{ [Cl 95\%] } & \\
\hline & & lower & upper & & & lower & upper & \\
\hline Subjective sleep quality & 1.522 & 0.977 & 2.370 & 0.063 & 1.024 & 0.765 & 1.371 & 0.872 \\
\hline Sleep latency & 0.876 & 0.623 & 1.207 & 0.399 & 1.010 & 0.805 & 1.266 & 0.934 \\
\hline Sleep duration & 1.540 & 1.002 & 2.367 & 0.049 & 1.344 & 1.008 & 1.790 & 0.044 \\
\hline Habitual sleep efficiency & 1.430 & 0.973 & 2.104 & 0.069 & 1.323 & 1.027 & 1.705 & 0.031 \\
\hline Sleep disturbance & 1.225 & 0.636 & 2.360 & 0.544 & 1.533 & 1.033 & 2.275 & 0.034 \\
\hline Use of sleeping medication & 1.221 & 0.742 & 2.007 & 0.432 & 0.695 & 0.387 & 1.247 & 0.222 \\
\hline Daytime dysfunction & 0.842 & 0.581 & 1.222 & 0.366 & 0.820 & 0.645 & 1.041 & 0.103 \\
\hline PSQI-BR global score & 1.073 & 0.943 & 1.223 & 0.286 & 1.029 & 0.942 & 1.124 & 0.524 \\
\hline
\end{tabular}


affect academic performance and increase stress (7). Studies associate stress with bruxism (4-6,15-18). Sleep bruxism is classified as a sleep-related movement disorder (23).

The present study found an association between awake bruxism, sleep disturbance and habitual sleep efficiency. The physiology and pathology of awake bruxism is not widely known, but emotional problems, anxiety and stress can be risk factors for this parafunction $(12,23)$. Habitual sleep efficiency is the proportion of time that the student sleeps compared with the total amount of time he or she spends in bed. It is a domain that refers to the total time that the student is in bed, and not only when sleeping $(19,20)$. Sleep efficiency affects the student the following day if he or she does not sleep for an adequate number of hours per night (20). The mean number of hours of sleep of the participants was below eight hours per night, which confirms an imbalance in the quality of sleep of students, affecting habitual sleep efficiency (21).

Sleep disturbances are conditions that can affect the quality of sleep, such as heat or cold, noise, light stimuli and stress (4). Anxiety and stress are considered risk factors for awake bruxism (23).

The student life is full of pressures and demands, which may result in stress and subsequently lead to the release of tensions by clenching the teeth $(2,3,11,13,14,23)$.

Cross-sectional studies are commonly used in epidemiological studies to analyze risk factors and associations, but not to evaluate causes. Longitudinal studies on this subject, with representative samples, should be performed (21).

The PSOI-BR is an instrument validated for a number of languages, widely used in sleep medicine research $(19,20,24,25)$ It is easy to apply and therefore is commonly recommended for epidemiological studies $(3,19-21)$. However, one limitation of the instrument is that it is based on self-reporting by participants $(3,19-21)$. Evaluations of sleep by polysomnography are more accurate (23) but involve more specialized equipment, resulting in increased financial costs (21).

In the same way, sleep bruxism and awake bruxism were evaluated from questions aimed at individuals. The question format was the same as that used in the PSOI-BR, a methodology similar to that used in the study of Dutch adolescents (17). Self-reported sleep bruxism and awake bruxism results were used in other studies (15-17).

Polysomnography can also be used to evaluate sleep bruxism (23). Evaluation using electronic instruments is more sophisticated and the practicality of using the PSOIBR should be reassessed (19-21).

The findings of the present study reveal that sleep quality is an important factor that affects dental students with sleep bruxism and awake bruxism. Attention should be directed to the quality of sleep of undergraduate students. Interdisciplinary educational campaigns should be encouraged, stressing the importance of the quality of sleep for the physical and emotional health of young people.

\section{Resumo}

0 objetivo deste estudo foi avaliar a associação entre o bruxismo do sono, bruxismo diurno e qualidade do sono entre estudantes de odontologia da Universidade Federal de Minas Gerais, Belo Horizonte, Brasil. Um estudo transversal foi desenvolvido com 183 estudantes de odontologia brasileiros com idade entre 17 e 46 anos. 0 curriculum completo do curso consiste de 9 semestres. Estudantes matriculados no primeiro semestre, no semestre do meio e no último semestre do curso participaram do estudo. O PSOI-BR (versão brasileira do Pittsburgh Sleep Questionnaire Index) foi utilizado para a coleta dos dados. O PSOI-BR foi distribuido em sala de aula. 0 diagnóstico de bruxismo do sono e bruxismo diurno foi baseado em auto-relato dos estudantes. Análise descritiva, Kruskal-Wallis, MannWhitney e regressão de Poisson com estimativa robusta foram os testes estatisticos utilizados. A prevalência do bruxismo do sono foi de $21,5 \% \mathrm{e}$ a prevalência do bruxismo diurno foi de $36,5 \%$. 0 componente duração do sono apresentou associação com bruxismo do sono $(\mathrm{PR}=1,540 ; 95 \% \mathrm{IC}$ : $1,00-2,37)$ e com bruxismo diurno ( $\mathrm{PR}=1,344 ; 95 \% \mathrm{Cl}: 1,008-1,790)$. Houve associação entre bruxismo diurno e o componente eficiência habitual do sono ( $\mathrm{PR}=1,323 ; 95 \% \mathrm{lC}: 1,03-1,70)$. 0 componente distúrbio do sono e o bruxismo diurno também apresentaram associação $(\mathrm{PR}=1,533 ; 95 \% \mathrm{IC}$ : $1,03-2,27)$. A má qualidade do sono foi um fator importante tanto entre os universitários que relataram bruxismo do sono quanto entre os que apresentaram bruxismo diurno.

\section{Acknowledgements}

Support for this study was provided by the following Brazilian funding agencies: the National Council for Scientific and Technological Development (CNPq), the Minas Gerais State Research Foundation (FAPEMIG) and Pro-Reitoria de Pesquisa of the Federal University of Minas Gerais (PRPq/UFMG).

\section{References}

1. Ming $X$, Koransky $R$, Kang V, Buchman S, Sarris CE, Wagner GC. Sleep insufficiency, sleep health problems and performance in high school students. Clin Med Insights Circ Respir Pulm Med 2011;5:71-79.

2. Medeiros AL, Mendes DBF, Lima PF, Araújo JF. The relationships between sleep/wake cycle and academic performance in medical students. Biological Rhythms Research 2001;32:263-270.

3. Kabrita CS, Hajjar-Muça TA, Duffy JF. Predictors of poor sleep quality among Lebanese university students: association between evening typology, lifestyle behaviors, and sleep habits. Nat Sci Sleep 2014;13:11-18.

4. Serra-Negra JM, Paiva SM, Fulgêncio LB, Chavez BA, Lage CF, Pordeus IA. Environmental factors, sleep duration, and sleep bruxism in Brazilian schoolchildren: a case-control study. Sleep Med 2014;15:236-239.

5. Abdulghani HM, Al-Drees AA, Khalil MS, Ahmad F, Ponnamperuma GG, Amin Z. What factors determine academic achievement in high achieving undergraduate medical students? A qualitative study. Med Teach 2014;36 Suppl 1:S43-S48.

6. Chinawa JM, Chukwu BF, Obu HA. Sleep practices among medical students in Pediatrics Department of University of Nigeria Teaching Hospital, Ituku/Ozalla, Enugu, Nigeria. Niger J Clin Pract 2014;17:232236.

7. Sweileh WM, Ali IA, Sawalha AF, Abu-Taha AS, Zyoud SH, Al-Jabi SW. Sleep habits and sleep problems among Palestinian students. Child Adolesc Psychiatry Ment Health 2011;15:5-25.

8. Cheng SH, Shih CC, Lee IH, Hou YW, Chen KC, Chen KT, Yang YK, Yang YC. A study on the sleep quality of incoming university students. Psychiatry Res 2012;197:270-274. 
9. Lemma S, Gelaye B, Berhane Y, Worku A, Williams MA. Sleep quality and its psychological correlates among university students in Ethiopia: a cross-sectional study. BMC Psychiatry 2012;12:237.

10. Serra-Negra JM, Paiva SM, Abreu MH, Flores-Mendoza CE, Pordeus IA. Relationship between tasks performed, personality traits, and sleep bruxism in Brazilian school children--a population-based crosssectional study. PLoS One 2013;8:e80075.

11. Angelone AM, Mattei A, Sbarbati M, Di Orio F. Prevalence and correlates for self-reported sleep problems among nursing students. J Prev Med Hyg 2011;52:201-208.

12. Paesani DA, Lobbezoo F, Gelos C, Guarda-Nardini L, Ahlberg J, Manfredini D. Correlation between self-reported and clinically based diagnoses of bruxism in temporomandibular disorders patients. J Oral Rehabil 2013;40:803-809.

13. Serra-Negra JM, Paiva SM, Auad SM, Ramos-Jorge ML, Pordeus IA. Signs, symptoms, parafunctions and associated factors of parentreported sleep bruxism in children: a case-control study. Braz Dent J 2012;23:746-752.

14. Strausz T, Ahlberg J, Lobbezoo F, Restrepo CC, Hublin C, Ahlberg $K$, Könönen $M$. Awareness of tooth grinding and clenching from adolescence to young adulthood: a nine-year follow-up. J Oral Rehabil 2010;37:497-500.

15. van Selms MK, Visscher CM, Naeije M, Lobbezoo F. Bruxism and associated factors among Dutch adolescents. Community Dent Oral Epidemiol 2013;41:353-363.

16. Serra-Negra JM, Tirsa-Costa D, Guimarães FH, Paiva SM, Pordeus IA. Evaluation of parents/guardian knowledge about the bruxism of their children: Family knowledge of bruxism. J Indian Soc Pedod Prev Dent 2013;31:153-158.

17. Bertolazi AN, Fagondes SC, Hoff LS, Dartora EG, Miozzo IC, de Barba $M E$, Barreto SS. Validation of the Brazilian Portuguese version of the Pittsburgh Sleep Quality Index. Sleep Med 2011;12:70-75.
18. Buysse DJ, Reynolds CF 3rd, Monk TH, Berman SR, Kupfer DJ. The Pittsburgh Sleep Quality Index: a new instrument for psychiatric practice and research. Psychiatry Res 1989;28:193-213.

19. Mondal P, Gjevre JA, Taylor-Gjevre RM, Lim HJ. Relationship between the Pittsburgh Sleep Quality Index and the Epworth Sleepiness Scale in a sleep laboratory referral population. Nat Sci Sleep 2013;5:15-21.

20. Lai PP, Say YH. Associated factors of sleep quality and behavior among students of two tertiary institutions in Northean Malaysia. Med J Malaysia 2013;68:196-203

21. Lavigne GJ, Khoury S, Abe S, Yamaguchi T, Raphael K. Bruxism physiology and pathology: an overview for clinicians. J Oral Rehabil 2008;35:476-494.

22. Serra-Negra JM, Paiva SM, Flores-Mendoza CE, Ramos-Jorge ML, Pordeus IA. Association among stress, personality traits, and sleep bruxism in children. Pediatr Dent 2012;34:e30-e34.

23. Serra-Negra JM, Ramos-Jorge ML, Flores-Mendoza CE, Paiva SM, Pordeus IA. Influence of psychosocial factors on the development of sleep bruxism among children. Int J Paediatr Dent 2009;19:309-317.

24. Nakajima S, Okajima I, Sasai T, Kobayashi M, Furudate N, Drake CL, et al.. Validation of the Japanese version of the Ford insomnia response to stress test and the association of sleep reactivity with trait anxiety and insomnia. Sleep Med 2014;15:196-202.

25. Ait-Aoudia M, Levy PP, Bui E, Insana S, de Fouchier C, Germain A, Jehel L. Validation of the French version of the Pittsburgh Sleep Quality Index Addendum for posttraumatic stress disorder. Eur J Psychotraumatol 2013;12:4.
Received February 28, 2014 Accepted June 3, 2014 